\title{
Clinical Study of the Prunus dulcis (Almond) Shell Extract on Tinea capitis Infection
}

Nasreen Thebo ${ }^{1 *}$, Altaf Simair², Wazir Sheikh', Abbasi AR ${ }^{3}$, Jabbar Laghari A ${ }^{4}$ and Hassan Nizamani M ${ }^{5}$

${ }^{1}$ Mycology Research laboratory Institute of Plant Sciences, University of Sindh, Jamshoro, Sindh, Pakistan

2Institute of Biotechnology \& Genetic Engineering, University of Sindh, Pakistan

${ }^{3}$ Faculty of Natural Science, University of Sindh, Pakistan

${ }^{4} \mathrm{Hi}$ Tech Laboratory, University of Sindh, Jamshoro, Pakistan

${ }^{5}$ Berlin Medical and Neuro Rehabilitation Hospital, Abu-Dhabi, UAE

\begin{abstract}
Prunus dulcis (Almond) shell extract demonstrated for its biomedical applications. Shell extract prepared by soxhlet method and further characterized by UV-Visible spectrophotometer, Atomic Absorption Spectrophotometer (AAS) and MIC control method. In this study the antifungal activity of almond shell extract was observed against clinically isolated pathogenic fungus by strip method. The antioxidant potential of crude shell extract was also evaluated by using DPPH (2-2-diphenyl-1-picryhydrazyl) and radical scavenging system. The total antioxidant activity varied from 94.38 to $95.49 \%$ and total phenolic content was found $4.455 \mathrm{mg} / \mathrm{g}$ in almond shell extract. Finally the results provide a great therapeutic potential against infection of scalp caused by Tinea capitis and result can be achieved in 20 days therapy. In this study of shell extract results provide a great therapeutic potential against infection of scalp caused by Tinea capitis and provides scientific evidence for clinical efficacy against dermatologic disorders. The present study is aimed to summarize the therapeutic importance of cheap and discarded coconut shell and the future prospects in order to develop a new generation of modern antimycotic drugs.
\end{abstract}

Keywords: Prunus dulcis (Almond); Tinea capitis; UV-Visible spectrophotometer

\section{Introduction}

The phyto-medicines derived from plants are still used in the developing countries and according to W.H.O it is estimated that $80 \%$ of the humans in the world mainly rely on traditional medicines for primary cure of health problems [1]. Nuts are considered to be one of the most nutritionally complete feed for human wellness due to their high nutritional contents such as carbohydrates, protein, unsaturated fatty acids, vitamins and essential minerals [2]. Nut consumption reduce the risk of cardiovascular disease (CHD), which may be partly explained by the cholesterol-lowering effect $[3,4]$. Several antimicrobial agentive roles were extracted and tested from the matrix and leaf of these species and many researchers are working to test in vitro effect of this work against bacteria, viruses, and fungi. Several nuts such as walnuts and peanuts are among this dietary work known to have significant antioxidant contents $[5,6]$. The stable radical species 1,1-diphenyl-2picrylhydrazyl (DPPH), has been widely used for antioxidant capacity cover and estimation due to its clear chemical reaction mechanism, solvent compatibility and the technical simplicity which requires no special equipment [7]. The shells can be used for fuel and are a source of charcoal [8] and excite carbon manufacturing from coconut shell is considered super effective for the firing of impurities [9]. Shells are the rough exterior part of the nuts [10] and are not used for food but can be utilized in several ways, including creating enriched potting soil and buff floor at household.

Tinea capitis is superintendent ficial dermatophyte characterized to form crust on the scalp, which is primary cause of hair loss. The dermatophytes which are most common cause of the disease is M. canis genus; M. gypseum; T. equinum; T. verrucosum; T. tonsurans; T. violaceum; and T. schoenleini [11]. The disease is always chronic, difficult to be treated or requires long term medicine and susceptible to have super infection with bacterial agents. Sweet almond possess a variety of beneficial properties affecting most notably cancer, high blood pressure, infectious diseases and diabetes but I am looking for nut shells a biodegradable material which can be used as potential reservoir for prevention of skin diseases.

\section{Material and Method}

\section{Shell Material}

Prunus dulcis (Almond) sample was collected at its optimum commercial maturity from the local market of Hyderabad. The Voucher specimen was deposited in herbarium at the Institute of plant science Figure 1.

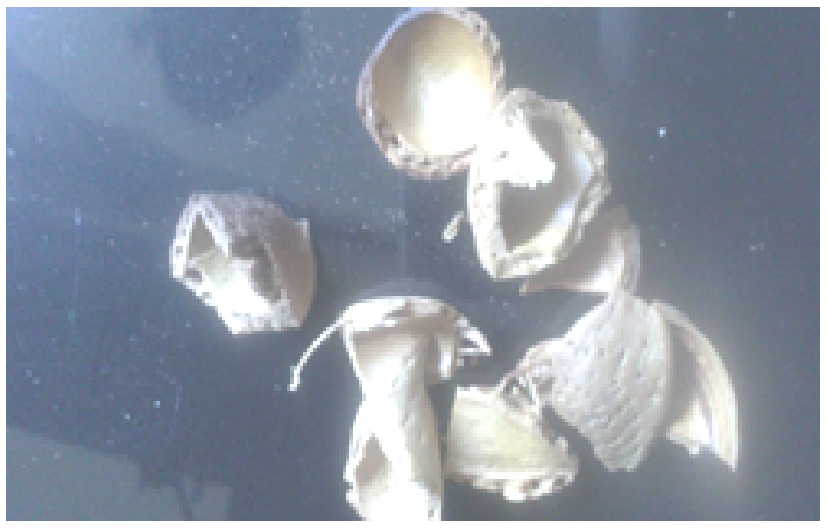

Figure 1: Prunus dulcis (Almond) sample.

${ }^{*}$ Corresponding author: Nasreen Thebo, Mycology Research laboratory Institute of Plant Sciences, University of Sindh, Jamshoro, Sindh, Pakistan, Tel: +923-332-723518; E-mail: nasreenthebo@gmail.com

Received March 03, 2014; Accepted April 23, 2014; Published April 28, 2014

Citation: Thebo N, Simair A, Sheikh W, Abbasi AR, Laghari JA, et al. (2014) Clinical Study of the Prunus dulcis (Almond) Shell Extract on Tinea capitis Infection. Nat Prod Chem Res 2 :131. doi:10.4172/2329-6836.1000131

Copyright: $\odot 2014$ Thebo N, et al. This is an open-access article distributed under the terms of the Creative Commons Attribution License, which permits unrestricted use, distribution, and reproduction in any medium, provided the original author and source are credited. 
Citation: Thebo N, Simair A, Sheikh W, Abbasi AR, Laghari JA, et al. (2014) Clinical Study of the Prunus dulcis (Almond) Shell Extract on Tinea capitis Infection. Nat Prod Chem Res 2 :131. doi:10.4172/2329-6836.1000131

Page 2 of 5

\section{Preparation of the Prunus dulcis shell extract}

The shell of almond powdered with the help of warring blender. $20 \mathrm{gm}$ of dried powder was filled in thimble and macerated with 100 $\mathrm{ml}$ of analytical grade solvent methanol. Sample was used by soxhlet extraction method for the formation of crude extract till 16 hours and kept on a rotary shaker for $24 \mathrm{~h}$. The sample was filtered through Whatman No. 1 filter paper to remove rough particles. The crude extract was stored at $18^{\circ} \mathrm{C}$ until analyzed.

\section{DPPH radical scavenging activity}

Free radical scavenging capacity of almond shell extract was determined according to the previous reported procedure using the stable 2, 2-diphenyl-1-picrylhydrazyl radical (DPPH) assay. The same DPPH assay method was reported by [12]. The absorbance of the resulting solution was read spectrophotometrically at $517 \mathrm{~nm}$ ). Fresh prepared solution of DPPH $(5.0 \mathrm{ml})$ was added to $1.0 \mathrm{ml}$ of shell extract. The decrease in absorbance measured at different intervals, i.e., $0.05,1,2,5$ and $10 \mathrm{~min}$ (up to $50 \%$ ) and $515 \mathrm{~nm}$ was determined with a Hitachi UV- Vis Spectrophotometer. The percentage of 2, 2-diphenyl1-picrylhydrazyl radical (DPPH) assay was calculated as follows:

$\% \mathrm{DPPH}$ scavenging $\left.=\left[\mathrm{A}_{\text {control }}-\mathrm{A}_{\text {sample }}\right) / \mathrm{A}_{\text {control }}\right] \times 100$.

Where $\mathrm{A}_{\text {sample }}$ is the absorbance of sample after the time necessary to reach the plateau $(30 \mathrm{~min})$ and $\mathrm{A}_{\text {control }}$ is the absorbance of DPPH. The remaining concentration of DPPH in the reaction mixture was calculated from a standard calibration curve.

\section{Determination of total phenolic content}

The total phenolic contents were extracted from shell of P.dulcis and determined by spectrophotometrically using the Folin-Ciocalteu method described previously (Moure A, et al 2007). The reaction mixture contains $200 \mu$ l diluted shell extract, $800 \mu$ lof freshly prepared and diluted Folin-ciocalteu reagent and $2 \mathrm{~m} 1$ of $7.5 \%$ sodium carbonate. The final mixture was diluted to $7 \mathrm{ml}$ with deionized water. Mixtures were kept in dark at ambient conditions for 2 hrs to complete the reaction and absorbance was measured at $767 \mathrm{~nm}$ on a Perkin - Elmer Lambda-2 spectrophotometer with a $1 \mathrm{~cm}$ cell. Gallic acid was used as standard and results were calculated as Gallic acid equivalents ( $100 \mathrm{~g}$ of shell). The experiments and the values reported are the average of two replicates of total phenolic contents. Gallic acid was used as the standard for a calibration curve and the phenolic content was reported as Gallic acid equivalents.

\section{Determination of elements}

Atomic absorption spectrophotometer and UV technique was used for the determination of elements. For this purpose, samples were digested with nitric acid and $30 \%$ hydrogen peroxide solution. Appropriate working standard solution of Calcium (Ca), Cadmium $(\mathrm{Cd})$, Chromium $(\mathrm{Cr})$, Copper $(\mathrm{Cu})$, Iron $(\mathrm{Fe})$, Potassium $(\mathrm{K})$ Magnesium (Mg), Manganese (Mn), Nickel (Ni), Zinc (Zn) and Cobalt (Co) were prepared from stock standard solution $(1000 \mathrm{ppm})$ in $2 \mathrm{~N}$ nitric acid. Calibration curves were drawn for each element using atomic absorption spectrophotometer (Hitachi model 180-50 ${ }^{\circledR}$ ).

\section{Collection of dermatophytes}

The samples were collected by scraping hair scalp and all fungal cultures were observed for (MIC) using strip method. Patients were observed clinically at skin department Liaquat University of Medical and Health Sciences, Hyderabad.

\section{Preparation of culture for dermatophytes}

Sabouraud's glucose agar was used to culture the fungi. Following composition was used for this purpose: peptone $10 \mathrm{~g}$, glucose $20 \mathrm{~g}$, agar $20 \mathrm{~g}$ and distilled water $1000 \mathrm{ml}$ with $\mathrm{pH}$ 5.4. All the contents were mixed and dissolved in distilled water. The solution was then autoclaved at $120^{\circ} \mathrm{C}, 15 \mathrm{lb} /$ inch $^{2}$ pressure for 20 minutes.

\section{Antimycotic screening}

The antifungal activity of Prunus dulcis (almond) shell extract was individually observed against dermal mycosis namely Aspergillus niger, Microsporum canis, Microsporum gypsum, Aspergillus flavus by strip method. The effect of shell extract on dermal mycosis was detected by measuring the diameter of colony obtained after incubation on treated plates and were compared with control. Each experiment was done in triplicates and average reading was recorded. Extract treated fungal plates were incubated at $37^{\circ} \mathrm{C}$ for 72 hours for fungi.

\section{Case Report}

05 year old patient was suffering from Tinea capitis (diagnosed clinically) 6 months before starting the treatment patient suffered with different sign and symptoms such as itching, radish coloration of skin and border inflammation (Figures 2-7).

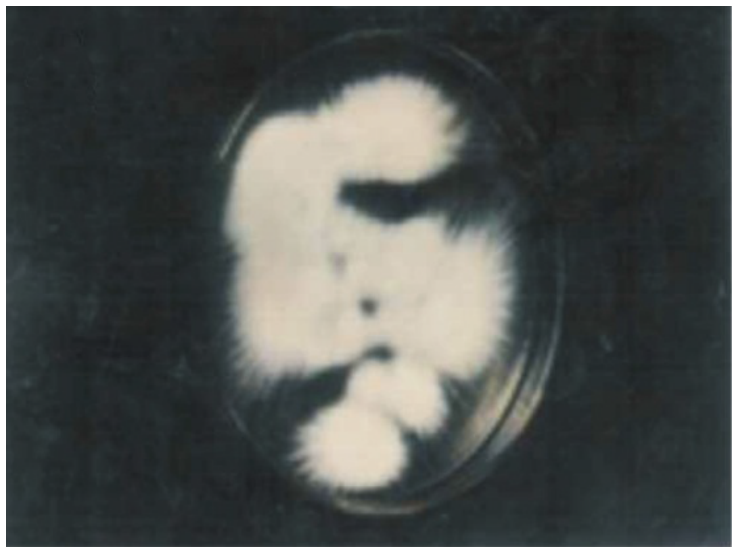

Figure 2: Showing colony on sabouraud agar $x$ 40. M.canis.

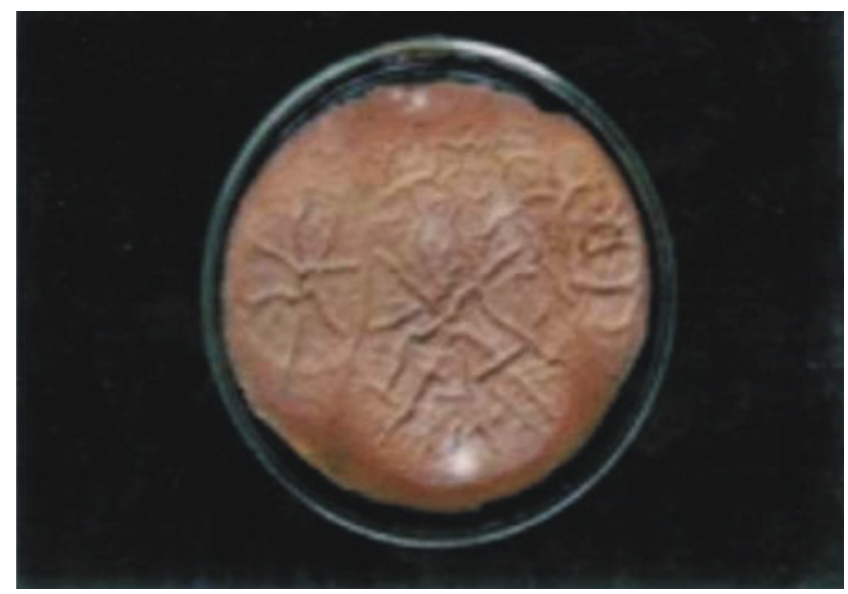

Figure 3: Showing colony on sabouraud agar x 40. M.gypsum. 


\section{Result and Discussion}

The modified Folin Ciocalteu reagent was used for the determination of total phenolic compounds and final result are expressed as Gallic acid eq. A Gallic acid standardization curvature ranging from 0.002 to 0.008 atomic number $12 \mathrm{lgm}$ was prepared and the results determined from the regression equation of the calibration curve $(y=1786 \mathrm{x}-0.0047$, curve $(y=1786 \mathrm{x}-0.00$ tetrad $7, \mathrm{R}=0.008$ were expressed as $\mathrm{mg}$ Gallic Acid Eq (GAE). In order to determine total phenolic content of hard shell Prunus dulcis $4.455 \mathrm{mg} / \mathrm{g}$ was dissolved in methanol. The phenolic compounds may contribute directly to antioxidative action [13]. The significant difference has been found and reported for TPC among the verities in the range of 2.51-3.5 $\mathrm{mg} \backslash \mathrm{g}$ for bran selection [14]. Deshpande [15] has determined differences in TPC extract in various solvents with highest antioxidant potential for the n-butanol extract of almond skin while the lowest antioxidant activity for methanol extract. $100 \%$ radical scavenging activity with assay method 2-2-diphenyl1picrylhydrazal (DPPH) was observed for shell selection at 100 and $200 \mathrm{ppm}$ concentration respectively. Amount resolution was seen at variation of time and results of these assays showed highest economic value at the time $30(\mathrm{~min}) 94.40$ whereas maximum divergence among the extract was observed at $0.5,1.0$ and fifteen min with the values 94.38 to 95.49 Graph 1. Similarly [16] observed the scavenging activity of extracts of almond skin and its by-product ranged from 67 to $97 \%$ DPPH. Highest values $90.40 \%$ were observed at 30 minutes whereas maximum difference among the seed extract was observed at $0.5,1.0$ and 15 minutes with the values $91.67,92.00$ and $93.32 \%$ respectively [17].

Radical scavenging burden of selection was analyzed using the bleaching of the stalls 1,1-diphenyl-deuce-picrylhydrazyl radical (DPPH) and found antioxidant natural process of ethyl alcohol extract from ground and roasted hazelnut and sugariness sweet almond pale yellow microbe [18]. Pinelo [19] evaluated the antioxidant potential from almond hull at the $85.20 \%$. The methanolic extract of the plant showed a strong dose-response antioxidant activity. Phenolic constituents had showed strong antioxidant activity against DPPH radical by spectrophotometric method whereas, Pinelo [19] detected

KINETIC STUDIES OF PRUNUS DULCIS (SHELL) SOXHLET DISTILLATION

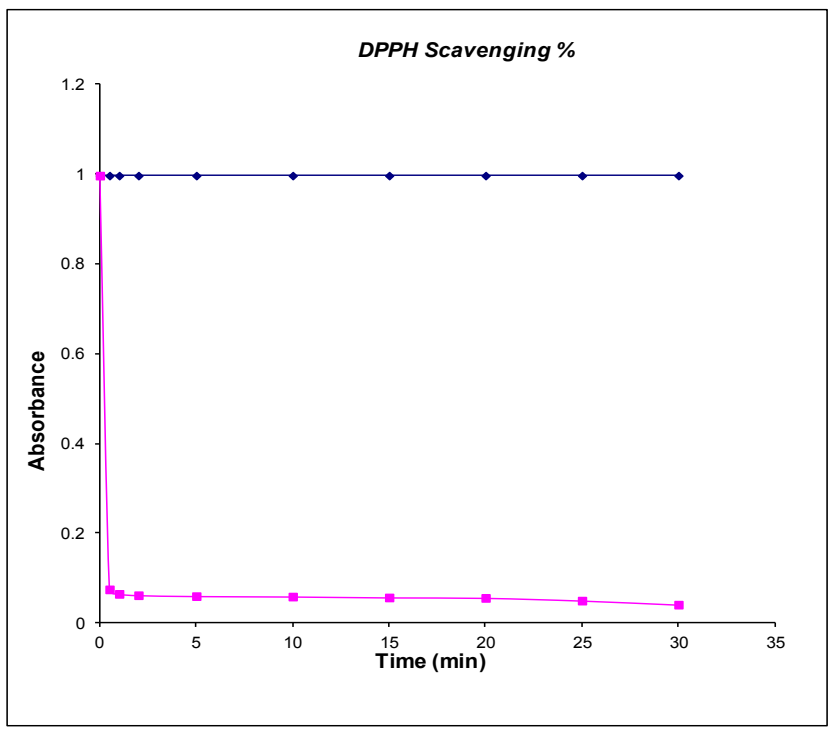

Graph 1: Kinetic studies of Prunus dulcis (shell) soxhlet distillation.

\begin{tabular}{|l|l|c|c|c|c|c|c|c|}
\hline \multicolumn{7}{|c|}{ Inhibition zone diameter $(\mathbf{m m})$} \\
\hline \multirow{2}{*}{ S. No. } & \multirow{2}{*}{ Microorganism } & \multicolumn{6}{|c|}{ Concentration of Shell extract By Strip Method } \\
\cline { 4 - 9 } & $\mathbf{1 0} \mathbf{\mu l}$ & $\mathbf{3 0} \mathbf{\mu l}$ & $\mathbf{5 0} \mathbf{\mu l}$ & $\mathbf{7 0} \mathbf{\mu l}$ & $\mathbf{8 0} \mathbf{~ \mathbf { l }}$ & $\mathbf{1 0 0} \boldsymbol{\mu l}$ & $\begin{array}{c}\text { Standard } \\
\text { Myconozole }\end{array}$ \\
\hline 1 & Aspergillus niger & 0.320 & 0.612 & 0.85 & 1.17 & 1.127 & 2.132 & 2.44 \\
\hline 2 & $\begin{array}{l}\text { Aspergillus } \\
\text { flavus }\end{array}$ & 0.84 & 1.122 & 1.14 & 1.71 & 1.89 & 1.80 & 2.3 \\
\hline 3 & $\begin{array}{l}\text { Microsporum } \\
\text { Canis }\end{array}$ & 0.245 & 0.524 & 0.749 & 1.141 & 1.172 & 2.630 & 2.6 \\
\hline 4 & $\begin{array}{l}\text { Microsporum } \\
\text { gypsum }\end{array}$ & 0.315 & 1.056 & 1.442 & 1.585 & 1.836 & 2.590 & 2.4 \\
\hline
\end{tabular}

Table 1: Antifungal activity of (Almond) shell extract of P.dulcis

\begin{tabular}{|c|c|c|c|}
\hline S/No. & Name Of Elements & Formula & Amount $\mathbf{~ m g} \mathbf{~ K g}$ \\
\hline 1. & Calcium & $\mathrm{Ca}$ & $11.75 \pm 25.56$ \\
\hline 2. & Cadmium & $\mathrm{Cd}$ & $0.938 \pm 0.002$ \\
\hline 3. & Chromium & $\mathrm{Cr}$ & $293.5 \pm 32.45$ \\
\hline 4. & Copper & $\mathrm{Cu}$ & $21.6 \pm 0.05$ \\
\hline 5. & Iron & $\mathrm{Fe}$ & $308.6 \pm 21.6$ \\
\hline 6. & Potassium & $\mathrm{K}$ & $705.2 \pm 20.4$ \\
\hline 7. & Magnesium & $\mathrm{Mg}$ & $264.1 \pm 0.04$ \\
\hline 8. & Manganese & $\mathrm{Mn}$ & $21.2 \pm 0.06$ \\
\hline 9. & Nickel & $\mathrm{Ni}$ & $6.22 \pm 0.35$ \\
\hline 10. & Zinc & $\mathrm{Zn}$ & $26.9 \pm 0.25$ \\
\hline 11. & Cobalt & $\mathrm{Co}$ & $6.33 \pm 0.02$ \\
\hline
\end{tabular}

Table 2: Elementology of Prunus dulcis (Almond).

total phenolic contents of the extract of pine sawdust and almond hulls but despite this, phenols from almond hulls showed a higher antioxidant capacitance (58 vs $34 \%$ ) of inhibition. This antioxidant activity has been thoroughly studied and a wide variety of methods have been developed to evaluate it. From the study, it can be concluded first time that $P$. dulcis shell has a higher level of antioxidant potential.

We determined trace elements from $P$. dulcis shell which are namely: Calcium $11.75 \mathrm{mg} / \mathrm{kg}$, Cadmium $0.938 \mathrm{mg} / \mathrm{kg}$, Chromium $293.5 \mathrm{mg} / \mathrm{kg}$, Copper $21.6 \mathrm{mg} / \mathrm{kg}$, Iron $308.6 \mathrm{mg} / \mathrm{kg}$, Potassium 705.2 $\mathrm{mg} / \mathrm{kg}$, Magnesium $264.1 \mathrm{mg} / \mathrm{kg}$, Manganese $21.2 \mathrm{mg} / \mathrm{kg}$, Nickel 6.22 $\mathrm{mg} / \mathrm{kg}$, Zinc $26.9 \mathrm{mg} / \mathrm{kg}$, Cobalt $6.33 \mathrm{mg} / \mathrm{kg}$ Table 2. Fungal infections remain a leading cause of chronic skin disease. Plants and animals depend on some metals as micro food. Metal 7 senses of element such as $\mathrm{Na}, \mathrm{K}, \mathrm{Ca}, \mathrm{Mg}, \mathrm{Fe}, \mathrm{Cu}, \mathrm{Zn}$ and $\mathrm{Mn}$, are necessary nutrients for human growth and some metals keep high level of exposure to some toxic metals, especially cadmium, chromium, atomic number 27, nickel and lead [20]. The detection of these trace metals in the vegetable oil color and seed requires specific analytical procedures such as emission and atomic absorption spectrophotometric proficiency as well as electroanalytical techniques [21]. The high chromium value of the shell and low level of anti-cadmium indicates its potentials usefulness in fungal infection, whereas nickel value 6.22 showed suppression of fungal mycelium so it can be responsible for the control of Tinea captis infection.

\section{Antimycotic assays}

Antifungal assays are generally performed by strip method. This method is qualitative test indicating resistance of micro organisms to the test material for fungicidal activity of P.dulcis shell antioxidant extract. The inhibitory effect of shell extract on the growth of dermal mycosis presented in Table 1. The antifungal activity of the P.dulcis shell extract was tested against 4 pathogenic fungi Aspergillus niger, Aspergillus flavus, M.canis, M.gypsum used in this experiment for 
inhibitory growth of extract. At concentration of $100,70,80, \mu l$ well, the extract has shown a remarkable antimycotic activities against the tested fungal species showed highest values of zones of inhibition between the ranges of 1.172-2.630 for M. canis, similarly M.gypsum inhibited at highest values between the ranges of 1.836-2.590. Different phenolic compounds of almond extract showed similar activity against trichophyton spp. being the most sensitive strain to these pure compounds. Naringenin showed the greatest inhibitory effect in the range of 250-500 $\mathrm{g} \mathrm{ml}^{-1}$. Gulluce observed the antimicrobial inhibitory effect of C. krusi from bacterial strains showed maximal inhibition zones. Antifungal effect showed positive healthy inhibitory effect on pathogenic fungi sensitive to shell extract were $1.75 \mathrm{~mm}$. Similar results were reported that $A$. niger showed lowest inhibition from 10 micro liter to 50 whereas it was suppressed at highest concentration 2.132. Inhibition of A. flavus was showed 1.80 with the high antioxidant potential.

Table 1 shows inhibitory effect on dermal mycosis with the therapeutic potential of $P$. dulcis shell extract were highly effective against all pathogenic fungi tested with the MIC ranging from initial $0.320 \mathrm{~mm}$ to final $2.590 \mathrm{~mm}$. The zone of inhibition increased on increasing the concentration of extract $P$. dulcis whereas lowest concentration also showed inhibitory effect at $10 \mu \mathrm{l}, 30 \mu \mathrm{l}$ and $70 \mu \mathrm{l}$. The efficacy of shell extracts was comparable with standard antimycotic drugs. Among different fungi tested M. canis and M. gypsum were found to be more sensitive to shell extract and present work has shown that Hard shell extract of almond was found to be most effective as an antifungal and antibacterial agent against human pathogenic fungi and results provide a therapeutic potential for microbial infections no doubt which can be used in assisting primary health care in Pakistan. The main object of this study is to provide scientific valid information by developing and

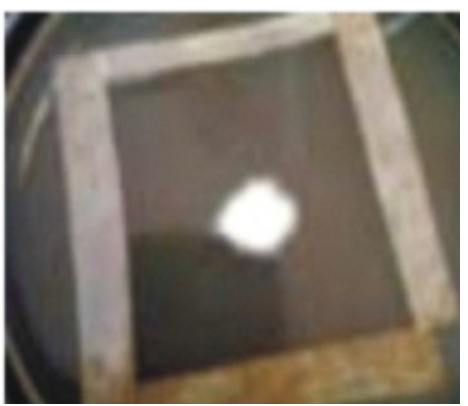

Figure 4: After Treatment; Inhibitory zones showing therapeutic effect on M.canis.

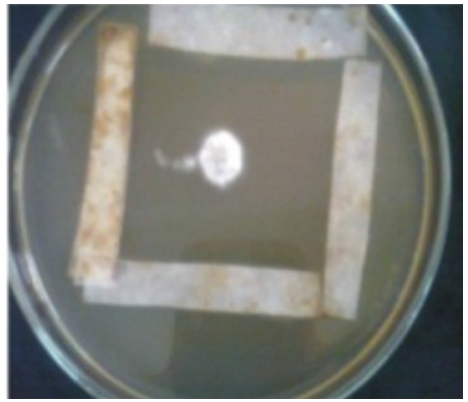

Figure 5: After Treatment; Inhibitory zones showing therapeutic effect on M.gypsum.

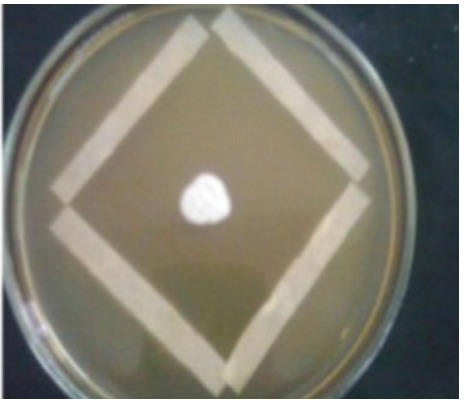

Figure 6: After Treatment; Inhibitory zones showing therapeutic effect on A.niger.

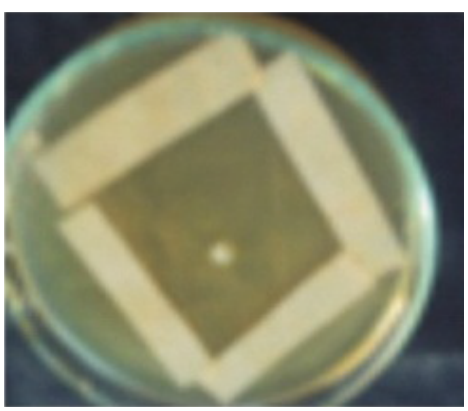

Figure 7: After Treatment; Inhibitory zones showing therapeutic effect on A.flavus MIC was recorded by strip method.

validating therapeutic and preventive approaches using the scientific method for all undeveloped hot and humid countries.

\section{Treatment}

The patient contacts a private dermatologist and received an antifungal compounds but no affect was noticed even after completing the course. Figure $8 \mathrm{a}-8 \mathrm{c}$ showed the Tinea capitis infection of the patient with mycological confirmation due to presence of fungal spores. Shell extract (about $1 \mathrm{gm}$ ) of the P.dulcis was applied in the form of 03 drops thrice a day on the affected area of the scalp. The patient baby showed recovery with complete removal of infected sign and symptoms of scalp. Reduction of itching, radish and inflammation of affected region showed potential inhibitory activity against $M$. canis and M. gypsum. Patient was completely recovered with removal of infection after 3 weeks without any side effects (Figures 8d). Patient has completely recovered with hair growth after a month of starting the treatment. Ring worm infection caused by dermatophytes is chronic with low recovery rate. Dermal mycosis is long term treatment and expensive even after disappearance of the fungal spores may germinate again and cause relapses [22]. According to the information collected from the patient she may suffer with insufficient healthy environment and malnutrition which would leads to the reappearance of the Tinea capitis infection. Hot and humid climate play a vital role in spreading the infection in Sindh, Pakistan. Successful treatment of Tinea capitis was observed by using $P$. dulcis and this indicates good affective antifungal activity of this cheapest waste material. Patient showed rapid recovery rate when the shell extract was applied thrice a day for three weeks, this result suggests the appropriate way of treatment (thrice/day for at least one month). We recommend the shell extract for patient's treatment with no side effects and no reoccurrence in future. 

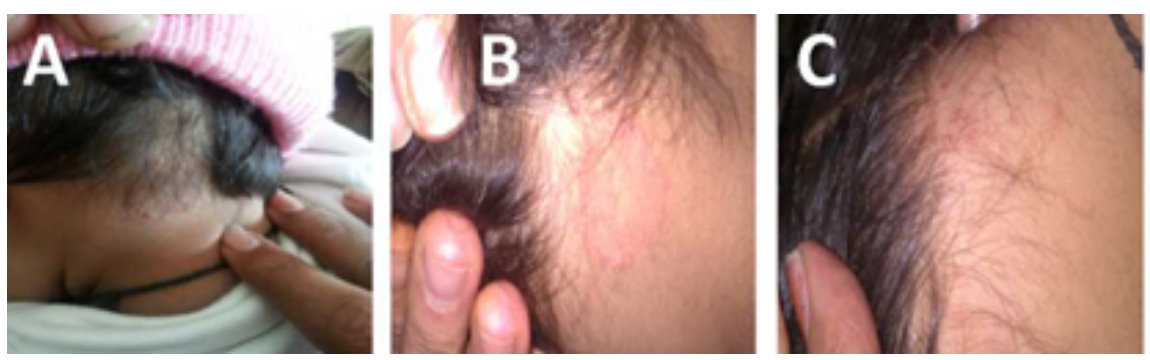

Figure 8a-8d: Clinically diagnosis Tinea capitis infection.

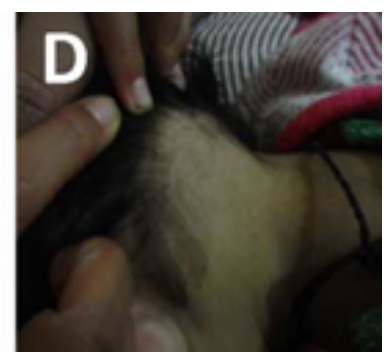

11. Dexter HH (1997) Ascomycetes the dermatophytes. In fungi pathogenic for human and animal. J Mykosen 12: 129-135

12. Costa AF (1975) Detection of phenolic compound and antioxidant properties of almond (Prunus amygdalus). J Farmacognosia 9: 986-989.

13. Lien EJ, Ren S, Bui HH, Wang R (1999) Quantitative structure-activity relationship analysis of phenolic antioxidants. Free Radic Biol Med 26: 285-294.

14. Yu L, Perret J, Harris M, Wilson J, Haley S (2003) Antioxidant properties of bran extracts from "Akron" wheat grown at different locations. J Agric Food Chem 51: $1566-1570$.

15. Deshpande SS, Sathe SK, Salunkhe DK (1984) Chemistry and safety of plant polyphenols. Adv Exp Med Biol 177: 457-495.

16. Sang S, Lapsley K, Jeong WS, Lachance PA, Ho CT, et al. (2002) Antioxidative phenolic compounds isolated from almond skins (Prunus amygdalus Batsch). J Agric Food Chem 50: 2459-2463.

17. Spiller GA, Jenkins DA, Bosello O, Gates JE, Cragen LN, et al. (1998) Nuts and plasma lipids: an almond-based diet lowers LDL-C while preserving HDL-C. J Am Coll Nutr 17: 285-290.

18. Koksal Al, Artik N, Simsek A, Gunes N (2006) Nutrient composition of hazelnut (Corylus avellana L.) varieties cultivated in Turkey. Food Chem 99: 509-515.

19. Pinelo M, Rubilar M, Sineiro J (2004) Extraction of antioxidant phenolics from almond hulls (Prunus amygdalus) and pine sawdust (Pinus pinaster). J Food Chem 85: 267-273.

20. Buldini PL, Ferri D, Sharma JL (1997 ) Determination of some inorganic species in edible vegetable oils and fats by ion chromatography. J Chromatogr A 789: 549-555.

21. Coco FL, Ceccon L, Ciraolo L, Novelli V (2003) Determination of cadmium (II) and zinc (II) in olive oils by derivative potentiometric stripping analysis. Food Control 14: 55-59.

22. Gulluce M, Sokmen M, Daferera D, Agar G, Ozkan H, et al. (2003) In vitro antibacterial, antifungal, and antioxidant activities of the essential oil and methanol extracts of herbal parts and callus cultures of Satureja hortensis L. J Agric Food Chem 51: 3958-3965. 